\title{
DA LESÃO CORPORAL CULPOSA NA CONDUÇÃO DE VEICULO AUTOMOTOR E A LEI FEDERAL № 13.546/2017
}

José Vitor de Araújo Biagi, Marcia Lucchino Ferreira, Luciana Claudia Silva Lima, Fabio Ferreira Morong

Universidade do Oeste Paulista - UNOESTE, Curso de Direito, Presidente Prudente, SP, E-mail: vitoraraujo 3@hotmail.com

\section{RESUMO}

O artigo busca a compreensão das alterações legais inseridas no Código de Trânsito Brasileiro através da Lei Federal no 13.546 de 2017, a qual incluiu a forma qualificada ao crime de Lesão Corporal Culposa praticado na condução de veículo automotor, dando-se pela ingestão de álcool ou outra substancia psicoativa que cause dependência. Pretende-se compreender os possíveis impactos da forma qualificada ao crime descrito, tipificado no §2 do artigo 303 do citado Código, bem como a eficácia coerciva aplicada ao ato e a execução das possíveis penas impostas ao condutor infrator. O método aplicado no desenvolvimento deste referido estudo foi o dedutivo legal, fundando-se na análise doutrinaria, na legislação nacional e na jurisprudência pertinente. Conclui-se que está evidente que a sociedade poderá experimentar uma sensação de impunidade, eis que, em que pese à legislação tenha agravado a pena aos condutores infratores, o seu cumprimento em regime fechado encontra, como visto, óbices de natureza jurídica, excetuandose em casos de reincidência e regressão.

Palavra-chave: Crimes de Trânsito, Lei 13.546/2017, Código de Transito Brasileiro, Lesão Corporal Culposa, Forma Qualificada

\section{OF THE BODY INJURY CAUSED IN THE DRIVING OF AN AUTOMOTIVE VEHICLE AND THE FEDERAL LAW 13.546/2017.}

\begin{abstract}
This article aims to understand the legal modifications included on the brazilian legal order by the Federal Law $\mathrm{n} 013.546$ of december 2017, that includes the qualified form of the wrongful bodily injury, practiced in driving a motor vehicle, , due alcohol or other psychoactive substance intake. It is intended to comprehend the possible impacts of the qualified form of the crime described, symbolized on the $\$ 20$ article 303 of the quoted Code, also the coercive effectiveness applied to the act and the execution of possible penalties applied to the ofender driver. The legal deduction method was applied along with the doctrinal analysis, national legislation and the jurisprudence relevant to the case. It is concluded that, even with a severe penalty applied to those defaulter, it is possible to exist a feel of impunity in the community, particularities aside, hardly the offender driver will face a closed penalty, except for cases of recidivism and regression.

Keywords: Traffic crimes, Law 13.546/2017, Brazilian Transit Code, Wrongful Bodily Injury, qualified form.
\end{abstract}




\section{INTRODUÇÃO}

O trabalho propõe uma breve análise da reforma à norma regulamentadora e o comparativo entre o tipo legal revogado e o vigente, sua tipicidade, forma qualificada e suas conseqüências penais, tendo sido promovida pela Lei 13.546 de dezembro de 2017, a qual teve sua efetiva vigência em 19 de abril de 2018, alterando, dentre outros, o artigo 303 do Código de Trânsito Brasileiro, que trata da Lesão Corporal Culposa quando na condução de veículo automotor.

Baseou-se ainda na efetiva compreensão da agravante em decorrência do consumo de álcool ou substancia psicoativa que determine dependência, estando esta, acompanhada do resultado de lesão grave ou gravíssima e, vislumbrando as possíveis penas a serem aplicadas ao condutor infrator, transpassando pelos institutos da prisão em flagrante, fiança e a substituição da pena, elucidando-se assim as finalidades originadas pelo legislador.

O objetivo é compreender as alterações legais inseridas no ordenamento jurídico brasileiro pela Lei Federal n. 13.546/17, especificamente à Federal no 9.053/1997, que regula o Código de Transito Brasileiro.

\section{METODOLOGIA}

O presente trabalho empregou pesquisas à legislação nacional, doutrinas e jurisprudências relevantes na matéria objeto de estudo. Utilizando o método dedutivo para sistematizar os dados coletados, a fim de cumprir o objetivo proposto.

\section{DA SIMETRIA}

O Código de Trânsito Brasileiro, em seu Capítulo XIV, trata as espécies de crimes de trânsito, especificamente o artigo 303, que cuida do crime de Lesão Corporal Culposa e sua forma qualificada, proporcionada pelo advento da nova lei.

O artigo 303 Código de Trânsito Brasileiro (BRASIL,1997) preceitua:

Art. 303: Praticar lesão corporal culposa na direção de veículo automotor:

Penas - detenção, de seis meses a dois anos e suspensão ou proibição de se obter a permissão ou a habilitação para dirigir veículo automotor.

$\S 2$ - A pena privativa de liberdade é de reclusão de dois a cinco anos, sem prejuízo das outras penas previstas neste artigo, se o agente conduz o veículo com capacidade psicomotora alterada em razão da influência de álcool ou de outra substância psicoativa que determine dependência, e se do crime resultar lesão corporal de natureza grave ou gravíssima. (Incluído pela Lei no 13.546, de 2017)

Destarte, verifica-se que através da lei 13.546/2017, houve a inclusão da qualificadora,

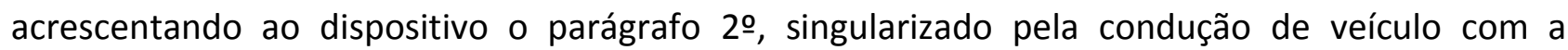
capacidade psicomotora alterada em razão da ingestão de álcool, ou outra substancia psicoativa que determine a dependência e a necessidade do resultado de lesão corporal de natureza grave ou gravíssima. Promove a pena de reclusão, de dois a cinco anos, além da suspensão ou proibição do direito de se obter habilitação para dirigir, ao passo que, antes da reforma mencionada, a pena cabível para o delito de lesão corporal de qualquer natureza era detenção, de dois a quatro anos e suspensão ou proibição do direito de dirigir.

Logo se abaliza a mudança na norma quando o legislador estabelece a possibilidade de iniciar o cumprimento da pena em regime fechado.

Segundo Carvalho (2015, p. 466):

“O próprio caput do art. 33 estabelece a diferença entre reclusão e detenção. A reclusão admitiria como regime inicial de cumprimento da pena as três modalidades previstas no código, ou seja, regimes fechados, semiaberto e aberto. A detenção, por ser uma espécie de pena cabível em delitos de menor gravidade, comportaria apenas o regime semiaberto e aberto." 
Carvalho (2015, p. 468), aponta que "o Código Penal, prevê a aplicação do regime fechado quando o julgador, ao realizar a dosimetria, fixar pena superior a 8 (oito) anos (art. 33, §2, a)".

Exterioriza-se assim, ante já exposta compreensão doutrinária e legal que, a imposição da pena em seu caráter mais rigoroso admitido pela reclusão não seria possível, já que, observada tal modalidade seria inerente a dosimetria que fixar pena superior a oito anos, evidenciando um contraponto ímprobo a pena fixada pela qualificadora, sendo esta de dois a cinco anos, salvo caso de reincidência ou regressão.

Acentua-se ainda que, ao proteger o bem jurídico no que tange a incolumidade física, o legislador não qualifica o fato típico apenas em decorrência da mera ingestão de substancia que determine a dependência, devendo também, o condutor, ter sua capacidade psicomotora alterada em decorrência desta ingestão e, ainda, causar a outrem, lesão corporal de natureza grave ou gravíssima.

\section{DA FORMA QUALIFICADA}

A forma qualificada do crime de lesão corporal culposa, caracterizada pelo consumo de álcool ou outra substancia análoga contemplada pelo Código de Trânsito é novidade. Apesar da reforma, o crime de lesão corporal culposa não obtinha qualquer preceito quanto à tipificação de ingestão destas substancias, ocorrendo apenas, punições na esfera administrativa, individualizada pelo art. 165 e 165 - A do CTB (BRASIL, 1997).

No tocante a suspensão ou proibição da habilitação, exemplificam Capez e Gonçalves (2015, p.16): “De acordo com o disposto no art. 292 do Código de Trânsito, pode ser imposta isolada ou cumulativamente com outras penalidades, devendo ter a duração de dois meses a cinco anos."

E ainda, os mesmos autores continuam relacionando tal proibição à lesão corporal culposa quando decorrente de acidente de transito (2015, p. 16):

Em crime de homicídio culposo e lesões corporais culposas praticados na condução de veículo automotor, direção em estado de embriaguez, violação de suspensão ou proibição e participação em competição não autorizada (racha), a lei prevê̂ expressamente a aplicação dessas penas conjuntamente com a pena privativa de liberdade e, em alguns casos, também com a pena de multa.

Apesar do Código de Trânsito Brasileiro tratar estes crimes de maneira individualizada em seu texto legal, o entendimento doutrinário e jurisprudencial consolidado era de que a lesão corporal em sua natureza culposa, sendo na condução de automotor e, havendo ainda a ingestão de álcool ou outra substancia que determine dependência, não cabia o concurso material de crimes e sim a absorção de crimes pelo princípio da consunção, onde o delito de lesão corporal absorvia o delito de embriagues ao volante, pois os respectivos tipos penais tutelam o mesmo bem jurídico, que só é atingido de maneira concreta no primeiro crime.

Nesse sentido, Capez e Gonçalves (2015, p. 38) explanam que:

..há de se ressaltar que a Lei 9.503/97 criou diversos crimes que se caracterizam por uma situação de perigo (dano potencial) e que ficarão absorvidos quando ocorrer o dano efetivo (lesões corporais ou homicídio culposo na direção de veículo automotor). É o caso dos crimes de embriaguez ao volante, direção de veículo sem habilitação, entrega da direção a pessoa não habilitada e excesso de velocidade em determinados locais (arts. $306,309,310,311$.

Destaca-se ainda que se o condutor trafegasse sob o efeito entorpecente e, por conta disso, ocasionasse acidente de transito tendo como consequência a lesão de terceiro, tal crime não encontrava abrigo no Código de Trânsito Brasileiro. 


\section{DOS EFEITOS}

É nítida a forma com que o legislador se atenta a este tema, em caráter geral, quanto às condições de álcool e drogas relacionadas ao trânsito. Para tanto, basta observar as transformações e evoluções normativas que sofreu a legislação pátria em seu código de transito em relação a este aspecto.

No tocante à cominação das penas tipificadas no texto legal, nota-se que, como consequência a severidade impetrada pelo legislador e, sob a óptica do Código de Processo Penal, mais especificamente ao instituto da prisão em flagrante, observando que a pena do tipo objetivo descrito no artigo é superior a quatro anos, a fiança não mais poderá ser imposta pela autoridade policial, devendo agora ser encaminhada ao juiz competente que, no prazo de até 48 (quarenta e oito) horas poderá decidir sobre o se arbitramento ou não.

Assim trata o Código de Processo Penal, em seu artigo 355 (BRASIL, 1941) descreve que a autoridade policial somente poderá conceder fiança nos casos de infração cuja pena privativa de liberdade máxima não seja superior a 4 (quatro) anos. Já seu parágrafo Único, prescreve que nos demais casos a fiança será requerida ao juiz, que decidirá em 48 (quarenta e oito) horas.

Marcão (2016, p. 1076) entende que:

"Também caberá ao juiz a fixação da fiança naqueles casos que extrapolam a alçada da autoridade policial - pena cominada superior a quatro anos. Apresentado o pedido, sobre ele o juiz deverá decidir em 48 horas, conforme regra contida no parágrafo único do art. 322 do CPP."

Diante disso, denota-se que o processo revelou-se mais rígido ao ponto de vista do infrator, sendo que deverá aguardar por até 48 (quarenta e oito) horas recluso, a decisão do magistrado que poderá ou não estabelecer fiança.

De outro lado, não se pode deixar de observar o disposto no artigo 301 do mesmo Código, já que este traz uma excludente da prisão em flagrante e reza que, havendo o pronto e integral socorro provido pelo condutor infrator, não será imposta a ele a prisão em flagrante, tampouco será exigida fiança.

Nota-se que o legislador almeja tutelar o bem jurídico que, em detrimento a infração ora causada, está em risco, sendo este a incolumidade física.

Capez e Gonçalves (2015, p. 31 e 32) entendem que "Acontece que, visando estimular o socorro às vítima, o legislador veda a efetivação da prisão em flagrante, bem como dispensa a fiança àquele condutor de veículo envolvido em acidente que venha a prestar imediato e completo socorro à vítima."

Por sua vez, é sabido que, crimes de natureza culposa são passiveis de substituição da pena privativa de liberdade em restritiva de direito, estando o transgressor do crime de lesão corporal culposa praticado na condução de veículo automotor resguardado pelos privilégios descritos no artigo 44 do Código Penal, como sucinta Capez e Gonçalves (2015, p. 18):

"De acordo com o Código Penal, tal pena tem caráter substitutivo da pena privativa de liberdade imposta na sentença ( $C P$, art. 44) pelo mesmo tempo de duração desta ( $C P$, art. 55) e é aplicável aos delitos culposos de trânsito (CP, art. 57)."

Destarte, o agente causador de fato crime amparado pela natureza culposa da ação, tem total competência para ensejar a substituição de crimes, podendo fazê-la, sem o desrespeito da agravante qualificada.

\section{CONCLUSÃO}

Com efeito, a preocupação do legislador quanto às políticas de contenção e represálias direcionadas ao condutor infrator é evidente, de modo que vem buscando deixá-los mais 
conscientes em relação perigos e riscos oriundos da ingestão de substancias que propiciam dependência combinadas com a condução de veículo automotor.

O êxito que se busca se opera por meio da majoração da pena imposta àqueles condutores que causam o efeito lesão a terceiros, e ainda, sob o efeito de substancia entorpecente. Importante ressaltar que, em razão de pouco tempo de vigência da aludida lei, de fato é prematuro para demonstrar os aspectos positivos e negativos da citada lei, de modo que, apenas em um breve futuro é que avaliações mais concretas serão capazes de avaliar com mais propriedade os efeitos esperados da aplicação da legislação aqui estudada.

Logo, conclui-se que, está evidente que a sociedade poderá experimentar uma sensação de impunidade, eis que, em que pese a legislação tenha agravado a pena aos condutores infratores, 0 cumprimento de pena em regime fechado encontra, como visto, óbices de natureza jurídica, excetuando-se, em casos de reincidência e regressão.

\section{REFERÊNCIAS}

BIAGI, J.V.A. Impactos normativos e práticos da lei 13.546/2017. p. 49. Trabalho Acadêmico, Direito Penal - Curso de Direito. Universidade do Oeste Paulista - Unoeste, Presidente Prudente, 2018.

BRASIL. DECRETO № 2.848, DE 07 DE dezembro DE 1940. Código Penal, Brasília, DF, fev. 1991. Disponível em:< http://www.planalto.gov.br/ccivil_03/decreto-lei/Del2848compilado.htm.> Acesso em: 15 ago. 2018

BRASIL. DECRETO no 3.689, de 03 de outubro de 1941. Código de Processo Penal, Brasília, DF, jan 1942. Disponível em: <http://www.planalto.gov.br/ccivil_03/Decreto-LEi/Del3689.htm>. Acesso em: 15 ago. 2018

BRASIL, Lei no 9.503, de 23 de setembro de 1997. Institui o Código de Trânsito Brasileiro. Diário Oficial [da] República Federativa do Brasil, Brasília, 24 set. 1997. Disponível em: <http://www.planalto.gov.br/ccivil_03/LEIS/L9503Compilado.htm>. Acesso em 11 ago. 2018

BRASIL. Lei no 13.546 de 19 de dezembro de 2017. Altera dispositivos da Lei $n^{\circ} 9.503$, de 23 de setembro de 1997 (Código de Trânsito Brasileiro), para dispor sobre crimes cometidos na direção de veículos automotores. Disponível em: < http://www.planalto.gov.br/ccivil_03/_Ato20152018/2017/Lei/L13546.htm>. Acesso em 11 ago. 2018.

CAPEZ, Fernando; GONÇALVES, Victor Eduardo Rios. Aspectos criminais do código de trânsito brasileiro. 3ำ ed. São Paulo - SP: Saraiva, 2015.

CARVALHO, Salo de. Penas e medidas de segurança no direito penal brasileiro. 20 ed. São Paulo SP: Saraiva, 2015.

CESPEDES, Lívia; ROCHA, Fabiana Dias da. Vade mecum saraiva OAB. 14ำ ed. São Paulo - SP: Saraiva, 2018.

MARCÃO, Renato. Código de processo penal comentado. São Paulo - SP: Saraiva, 2016. p. 1076. MARINARI, Fábio. Crimes de trânsito. Disponível em: https://marinari.jusbrasil.com.br/artigos/544801119/crimes-de-transito?ref=serp. Acesso em: 31 de jul. 2018 
MATOS, Fabrícia de. Crimes de trânsito e a vedação da prisão em flagrante quando há prestação de socorro à vítima. Disponível em: https://fabriciamatosadv.jusbrasil.com.br/artigos/607157287/crimes-de-transito-e-a-vedacaoda-prisao-em-flagrante-quando-ha-prestacao-de-socorro-a-vitima?ref=serp. Acesso em: 07 de ago. 2018.

MOLETA, Paulo. A origem do trânsito e do CTB. Disponível em: https://paulocwb.jusbrasil.com.br/artigos/206526711/a-origem-do-transito-e-do-ctb. Acesso em: 30 de abr. 2018

SÃO PAULO. Tribunal de Justiça de São Paulo, 1a Câmara Criminal Extraordinária TJ-SP. Apelação no: 0002283-68.2010.8.26.0673. SP. Ementa: - Autoria e materialidade delitivas demonstradas Confissão judicial parcial - Absorção do crime de embriaguez (delito de perigo) pelo homicídio (crime de dano) - Princípio da consunção - Absolvição - Condenação mantida somente pelo homicídio culposo. Relator: Nelson Fonseca Junior. Data de Julgamento: 25/06/2015, Data de Publicação: 30/06/2015. Disponível em: https://tjsp.jusbrasil.com.br/jurisprudencia/204212240/apelacao-apl-22836820108260673-sp-00022836820108260673?ref=serp Acesso em: 08 de ago. 2018. 